https://helda.helsinki.fi

\title{
Laboratory verification of a new high flow differential mobility particle sizer, and field measurements in Hyytiälä
}

\section{Kangasluoma, Juha}

2018-10

Kangasluoma , J , Ahonen , L R , Laurila , T M , Cai , R, Enroth , J , Mazon , S B , Korhonen , F , Aalto , P P , Kulmala , M , Attoui , M \& Petäjä , T 2018 , ' Laboratory verification of a new high flow differential mobility particle sizer, and field measurements in Hyytiälä ' , Journal of Aerosol Science , vol. 124 , pp. 1-9 . https://doi.org/10.1016/j.jaerosci.2018.06.009

http://hdl.handle.net/10138/317674

https://doi.org/10.1016/j.jaerosci.2018.06.009

cc_by_nc_nd

acceptedVersion

Downloaded from Helda, University of Helsinki institutional repository.

This is an electronic reprint of the original article.

This reprint may differ from the original in pagination and typographic detail.

Please cite the original version. 
1 Laboratory verification of a new high flow differential mobility particle sizer, and field measurements

2 in Hyytiälä

3 Juha Kangasluoma ${ }^{1,2 *}$, Lauri R. Ahonen ${ }^{1}$, Tiia M. Laurila ${ }^{1}$, Runlong Cai ${ }^{1,3}$, Joonas Enroth ${ }^{1}$, Stephany

4 Buenrostro Mazon ${ }^{1}$, Frans Korhonen ${ }^{1}$, Pasi P. Aalto ${ }^{1}$, Markku Kulmala ${ }^{1,2}$, Michel Attoui ${ }^{1,4}$, Tuukka

5 Petäjä ${ }^{1}$

6

$7 \quad{ }^{1}$ Institute for Atmospheric and Earth System Research / Physics, Faculty of Science, University of

8 Helsinki, P.O. Box 64, 00014 Helsinki, Finland

$9 \quad{ }^{2}$ Aerosol and Haze Laboratory, Beijing Advanced Innovation Center for Soft Matter Science and

10 Engineering, Beijing University of Chemical Technology, 100029 Beijing, China

$11{ }^{3}$ State Key Joint Laboratory of Environment Simulation and Pollution Control, School of

12 Environment, Tsinghua University, 100084 Beijing, China

${ }^{4}$ University Paris Est Creteil, University Paris-Diderot, LISA, UMR CNRS 7583, France

*Correspondence to: Juha Kangasluoma, juha.kangasluoma@helsinki.fi

Abstract

Measurement of atmospheric sub-10 nm nanoparticle number concentrations has been of substantial interest recently, which, however, is subject to considerable uncertainty. We report a laboratory characterization of a high flow differential mobility particle sizer (HFDMPS), which is based on the Halfmini type differential mobility analyzer (DMA) and nano condensation nuclei counter (A11), and show the first results from atmospheric observations. The HFDMPS utilizes the state-of-the-art aerosol technology, and is optimized for sub-10 nm particle size distribution measurements by a moderate resolution DMA, optimized and characterized low-loss particle sampling line and minimal dilution in the detector. We present an exhaustive laboratory calibration to the HFDMPS and compare the 
measured size data to the Hyytiälä long-term DMPS and Neutral cluster and ion spectrometer. The HFDMPS detects about two times higher 3-10 nm particle concentrations than the long-term DMPS, and the counting uncertainties are halved as compared to the long-term DMPS. The HFDMPS did not observe any sub-2.5 nm particles in Hyytiälä, and the reason for that was shown to be the inability of diethylene glycol to condense on such small biogenic particles. Last, we discuss the general implications of our results to the sub-10 nm DMPS based measurements.

1 Introduction

A Differential / Scanning Mobility Particle Sizer (DMPS/SMPS) (Wiedensohler et al. 2012) is the most commonly used instrument to obtain particle number size distributions. DMPS systems are operated continuously in more than 30 sites around the world (Aalto et al. 2001; Asmi et al. 2013; Dada et al. 2017; Rose et al. 2015; Tuch et al. 1997; Wehner and Wiedensohler 2003). Usually a DMPS system measures the particle number size distribution between 10 and $800 \mathrm{~nm}$, while some ultrafine DMPS systems extend down to $3 \mathrm{~nm}$. The particle size distribution is used to infer various derivative parameters, such as particle surface area, formation and growth rate, and condensation sink (Kulmala et al. 2012). These parameters are used in studies on the effects of aerosol particles to climate and human health. Overall, the aerosol number size distribution is a versatile parameter in atmospheric and aerosol science and therefore accurate size distribution measurements are of great interest.

The traditional DMPS system consists of a sampling line, aerosol charger, differential mobility analyzer (DMA), condensation particle counter (CPC), and an inversion code to back-calculate the size segregated particle concentration at the DMPS inlet from the particle concentration detected by the CPC (Pfeifer et al. 2014; Wiedensohler et al. 2012). A conventional DMPS sampling line inlet is a preimpactor to remove particles larger than $2.5 \mu \mathrm{m}$, which can be highly charged, and a drier to make the measurements more comparable between observation sites. These two together with e.g. long 
sample tubing, flow splits and valves can cause particle losses. This is particularly important for the sub-10 $\mathrm{nm}$ particles, which are efficiently lost by Brownian motion to the inlet line walls. The outlet of the sampling line is connected to an aerosol charger, which produces a cloud of bipolar small ions that diffuse and transfer charge to the particles. According to the current knowledge the charged fractions of sub-10 nm particles are in the range of $0.5-5 \%$ depending on their size (Fuchs 1963; Wiedensohler 1988), while more recent studies suggest even lower charging probabilities at molecular sizes (Fernández de la Mora 2011). Thus, downstream of the charger the concentration of the charged particles entering the DMA is often low. As a summary, all the previous instrumental factors lead to the fact that the limit of detection of the DMPS systems are usually in the range of 10$1000\left(\mathrm{~cm}^{-3}\right.$ in $\left.\mathrm{dN} / \mathrm{dlog}_{10} \mathrm{D}_{\mathrm{p}}\right)$ in the sub-10 nm size range (Aalto et al. 2001). Taking into account these factors in the inversion, a single count in the DMPS system translates into tens or hundreds of particles in the inverted size distributions.

Often, especially in the sub-10 nm size range, the number of counted particles, $\mathrm{N}_{c}$, by the CPC can be low as discussed above, leading to counting uncertainties in the inverted concentration. This is because the particle sampling is a random Poisson process, in which the relative counting uncertainty can be estimated as $\mathrm{VN}_{\mathrm{c}} / \mathrm{N}_{\mathrm{c}}$ (Kangasluoma and Kontkanen 2017). Further, inaccuracies in the inversion can originate from the characterization (or lack of it) of the sampling lines, charging probability and DMA penetration. All of these errors accumulate to the particle concentrations measured by the DMPS systems, making the sub-10 nm particle concentrations highly inaccurate (Figure 5 in Wiedensohler et al. 2012). because of a lack of a suitable detector. In 2011 Jiang et al. (2011b) put forward the first efforts to apply DMPS technology to detect atmospheric sub-3 $\mathrm{nm}$ size segregated particle concentrations. The SMPS of Jiang and co-workers (Jiang et al. 2011a) is similar to the DMPS system described above, the main difference being the diethylene glycol (DEG) based CPC used as the detector capable of counting the particles down to $1 \mathrm{~nm}$ (lida et al. 2009). While the pioneering instrument of Jiang and co-workers 
stretched the capabilities of the DMPS technology, their instrument still suffers from most of the challenges of a DMPS system presented above. The "DMA train" developed by Stolzenburg et al. (2017) partly solves the challenge of low counting statistics with long counting time. However, because of many separate DMA-CPC pairs measuring in parallel, it is more complex and expensive than a conventional DMPS system.

In this study we characterize a high flow DMPS (HFDMPS) which utilizes the state-of-the-art sub-10 $\mathrm{nm}$ aerosol technology: a core sampling system to minimize particle transport losses (Kangasluoma et al. 2016b), SEADM Half-mini type DMA (Fernández de la Mora and Kozlowski 2013), and Airmodus A11 (Vanhanen et al. 2011). Our goal is to optimize the DMPS technology that is applicable to atmospheric measurements in every aspect for sub-10 nm particle measurements. We characterize the HFDMPS system for particle penetration in the sampling line, charger, DMA and for the detection efficiency of the detector. The HFDMPS was operated at Station for Measuring Ecosystem - Atmosphere Relations (SMEAR) II station (Hari and Kulmala 2005) in Hyytiälä, Finland. The atmospheric sub-10 nm size distributions and particle concentrations obtained with the HFDMPS were compared to the Hyytiälä long term DMPS and Neutral cluster and Air lon Spectrometer (NAIS).

\section{Experimental}

\subsection{Description of the HFDMPS}

When using the HFDMPS (Figure 1) in ambient experiments, the sample is drawn from the atmosphere through a horizontal $50 \mathrm{~cm}$ long and $10 \mathrm{~mm}$ outer diameter (OD) steel tube with a flow rate of $10 \mathrm{~L} / \mathrm{min}$. No pre-impactor was used. Downstream of this main sampling line the HFDMPS utilizes core sampling, subsampling $5 \mathrm{~L} / \mathrm{min}$ from the center of the $10 \mathrm{~mm}$ tube and approximately retrieving the atmospheric particle concentration (Kangasluoma et al. 2016b). The excess flow of 5 $\mathrm{L} / \mathrm{min}$ by-passes the instrument. Next, the sample is guided to a ${ }^{14} \mathrm{C}$ radioactive charger, of which 
housing is a metal cylinder of $30 \mathrm{~mm}$ in diameter and $120 \mathrm{~mm}$ long. The source activity is $370 \mathrm{MBq}$

105

106

107

108

109

110

111

112

and it is attached at the top plate inside the housing. $4 \mathrm{~mm}$ inner diameter air inlet and outlet are placed close to the top and bottom of the cylinder (Figure 1). The charger is followed by the long/fat $\left(R_{1}=4 \mathrm{~mm}, \mathrm{R}_{2}=7 \mathrm{~mm}, \mathrm{~L}=20 \mathrm{~mm}\right.$ ) Half-mini type DMA (Fernández de la Mora and Kozlowski 2013). The DMA is operated at sheath flow rate of $100 \mathrm{~L} / \mathrm{min}$ and aerosol flow rate of $5 \mathrm{~L} / \mathrm{min}$ in recirculating mode (Jokinen and Mäkelä 1997). The sheath flow loop includes a blower, flow meter, air cooler, and a high efficiency particulate arrestance (HEPA) filter. With this arrangement, the pressure drop over the DMA is approximately $2 \mathrm{kPa}$. The negative classifying voltage of the DMA is stepped in 5 min with 20 logarithmic steps between 90 and $5000 \mathrm{~V}$. This converts to a size distribution measurements from 1.5 to $10 \mathrm{~nm}$ in mobility diameter. The counting time at each voltage step is $10 \mathrm{~s}$ with a $5 \mathrm{~s}$ waiting time in between each of the voltage step.

Downstream of the DMA outlet the Airmodus A11 (Vanhanen et al. 2011) detects the size classified particles. As the inlet flow rate of the $\mathrm{A} 11$ is $2.5 \mathrm{~L} / \mathrm{min}$, an additional bypass flow of $2.5 \mathrm{~L} / \mathrm{min}$ is added downstream of the DMA to increase the particle penetration through the DMA. A11 is a mixing type CPC operated with DEG as the working fluid. The sample flow rate of $2.5 \mathrm{~L} / \mathrm{min}$ is conditioned to $40^{\circ} \mathrm{C}$ and mixed with a flow that is heated up to $70-85^{\circ} \mathrm{C}$ and saturated with DEG. The mixed flow is taken into a cold growth tube with a temperature conditioning to $1-5{ }^{\circ} \mathrm{C}$ where particle growth takes place. The particles grow up to around $90 \mathrm{~nm}$ and are subsequently taken into a butanol CPC (Airmodus A20) which counts the grown particles. By scanning the flow rate going through the saturator, it is possible to scan the supersaturation with respect to DEG. This varies the lowest detectable particle diameter approximately in the size range from 1 to $3 \mathrm{~nm}$ (Lehtipalo et al. 2014). In this study the A11 is operated at a fixed supersaturation with a flow rate of $1 \mathrm{~L} / \mathrm{min}$ going through the saturator.

The Hyytiälä long-term DMPS (Aalto et al. 2001) is a twin-DMPS system. The DMPS samples through the roof of the Hyytialä main aerosol cottage with the inlet at the height of $8 \mathrm{~m}$. The main sampling line has a large flow rate of $150 \mathrm{lpm}$ and $10 \mathrm{~cm}$ OD main sampling tube to bring the 
particles to various instruments. The DMPS samples from that flow through a $6 \mathrm{~mm}$ OD core sampling with an inlet flow rate of $5 \mathrm{lpm}$, which is dried with a silica gel drier. $\mathrm{A}^{14} \mathrm{C}$ radioactive aerosol charger, similar to the one of the HFDMPS, is placed upstream of the twin-DMPS system, downstream of which two Hauke type DMAs (Winklmayr et al. 1991) are operated in parallel. The short DMA is operated with an aerosol flow rate of $4 \mathrm{lpm}$ and sheath flow rate of $20 \mathrm{lpm}$ followed by a TSI 3776 with undiluted aerosol flow rate of $0.05 \mathrm{~L} / \mathrm{Min}$. This ultrafine part of the DMPS measures particle size distribution between 3 and $40 \mathrm{~nm}$. The long DMA operates at flow rates of $1 \mathrm{lpm}$ aerosol flow rate and $5 \mathrm{lpm}$ sheath flow rate, and uses a TSI 3772 as the detector. The fine DMPS measures particles size distribution between $15 \mathrm{~nm}$ and $1000 \mathrm{~nm}$. A more in-depth characterization of the Hyytiälä DMPS system is given in Aalto et al. (2001).

Neutral cluster and air ion spectrometer (NAIS, Manninen et al. 2016; Mirme and Mirme 2013) measures ion and particle size distributions in the size range of $0.8-40 \mathrm{~nm}$ and $2-40 \mathrm{~nm}$, respectively. The NAIS samples directly the atmospheric air with an inlet flow rate of $54 \mathrm{lpm}$, which is split into two channels to measure the particle size distribution via positive and negative corona charging, or ion size distribution without charging. The charged particles and ions are subsequently classified with a DMA column, which is composed of 21 insulated electrometer rings as the outer electrode. With a known geometry, classifying voltages and flow rates, each electrometer represents a fixed electrical mobility bin. Presuming a known unipolar charge equilibrium created by the corona needles, the currents measured by the NAIS electrometers can be converted into a particle number size distribution (Mirme and Mirme 2013).

During the atmospheric measurements these two instruments sample approximately $20 \mathrm{~m}$ away from the HFDMPS, and the sub-10 nm size distributions measured by these instrument are used as a reference for the HFDMPS. 


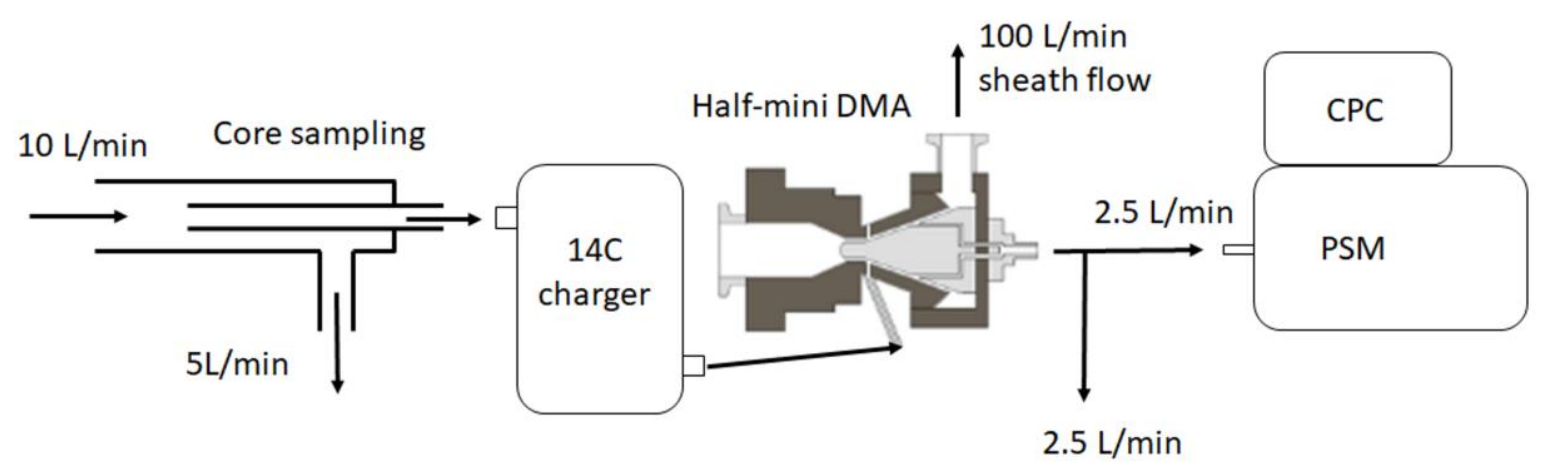

153

154 Figure 1. Schematic figure of the HFDMPS.

2.2 Characterization of the HFDMPS

157

We characterized the size dependent particle penetration through the core sampling line,${ }^{14} \mathrm{C}$ charger,

DMA and t-split at the flow rates described in the previous section. The total penetration, $P$, through the HFDMPS system is described as a product of penetrations through the individual parts as follows:

$P\left(D_{p}\right)=P_{\text {line }}\left(D_{p}\right) \cdot f_{c}\left(D_{p}\right) \cdot P_{D M A}\left(D_{p}\right)$

where $P$ is the total particle penetration probability from the HFDMPS inlet to the CPC optics, $D_{p}$ is particle diameter, $P_{\text {line }}$ is the product of penetrations through the sampling line, charger, $\mathrm{t}$-split and the PSM, $f_{c}$ is the fraction of positively singly $(+1)$ charged particles (Wiedensohler 1988), and $P_{D M A}$ is the penetration through the Half-mini DMA. $P_{D M A}$ was estimated according to the following relationship (Stolzenburg et al. 2018):

169

$\left.\frac{N_{2}}{N_{1}}\right|_{D_{p}{ }^{*}}=P_{D M A}\left(D_{p}\right) \times \Omega\left(f_{v} \cdot D_{p}{ }^{*}, D_{p}, \sigma\right)$

where $N_{1}$ is the particle number concentration upstream of the DMA, $N_{2}$ is the concentration downstream of the DMA, $\Omega$ is the empirical diffusional transfer function (Eq. 13 in Stolzenburg and McMurry 2008), $f_{v}$ is a voltage adjustment parameter, $D_{p}{ }^{*}$ is the centroid diameter of the tested Half- 
mini DMA, and $\sigma$ is the diffusional parameter. When characterizing $P_{D M A}$ and $\Omega$ using a tandem DMA system, the voltage of the first DMA (a Herrmann type DMA operated at resolution of approximately 25) was fixed so that the selected particle size, $D_{p}$, was fixed. $D_{p}{ }^{*}$ increased gradually with the increasing voltage of the tested Half-mini DMA. $P_{D M A}, f_{v}$, and $\sigma$ were fitted to the data for each test particle diameter $\left(D_{p}\right)$. Note that the test particles were not completely monomobile because of the finite resolution of the first DMA, thus the fitted $\sigma$ was overestimated compared to the true $\sigma$ that characterizes particle diffusion and imperfections (e.g., the potential flow distortions in aerosol inlet slit) in the Half-mini DMA (Fernández de la Mora 2017). However, the influence of non-ideal test particles on the fitted $P_{D M A}$ was negligible although the test particles were not completely monomobile.

Eq. (1) is the traditional penetration characterization of a DMPS system. As especially in the sub- $5 \mathrm{~nm}$ particle concentration measurements the number of detected particles can be low because of the low $P$, the counting uncertainties can become significant. Therefore a better measure, the PtQ value, of a DMPS performance is used. This parameter combines all the parameters affecting the number of counted particles, and is calculated as

$P t Q\left(D_{p}\right)=-P\left(D_{p}\right) \cdot t \cdot Q \cdot \beta \cdot \frac{\operatorname{dln} D_{p}}{\operatorname{dln} z_{p}}$

where $P$ is the total penetration as in Eq. (1), $t$ is the counting time at each voltage, $Q$ is the undiluted aerosol flow rate in the CPC (in our case $(2.5 / 3.5) * 1 \mathrm{~L} / \mathrm{min}=0.7143 \mathrm{~L} / \mathrm{min}$ due to dilution in the PSM), $B$ is the DMA aerosol-to-sheath flow ratio and the product of $B$ and $-\mathrm{dln} d_{p} / \mathrm{d} \ln Z_{p}$ is the integral over the product of the DMA transfer function and dlnd (Stolzenburg and McMurry 2008). In essence, when the PtQ value is multiplied with the sampled particle concentration in terms of $d N / d \log D_{p}$, the result is the number of raw counts counted by the CPC. Since the smallest nonzero number of raw counts is 1 , which can be also considered as the DMPS limit of detection (LOD, $\mathrm{cm}^{-3}$ in $\mathrm{dN} / \operatorname{dlog} \mathrm{D}_{\mathrm{p}}$ ), the inverse of PtQ, 1/PtQ, gives the DMPS LOD. In our case the DMPS limit of detection can be calculated 
as LOD $=3^{*} \operatorname{In}(10) / P t Q$. With this definition the LOD is defined as three counts during a measurement due to possible background count interference of one or two raw counts, and $\ln (10)$ converts the $\mathrm{dN} / \mathrm{d} \log \mathrm{D}_{\mathrm{p}}$ to 10 base logarithm.

The general approach to characterize the different parts of the HFDMPS was to measure the particle concentration of a known size upstream and downstream of the each of the measurement components, and compare the ratio of the detected particles. The test particles were generated with a glowing wire generator using $\mathrm{NiCr}$ wire (Kangasluoma et al. 2015b; Peineke et al. 2006) and size classified with a Herrmann type DMA (Kangasluoma et al. 2016a) operating at resolution (Z/ $\Delta Z$ ) (Flagan 1999) of approximately 25 . Downstream of the generator the particles were charged with a ${ }^{241} \mathrm{Am}$ radioactive charger. From earlier mass spectrometric measurements we know that the particle composition with this configuration is $\left(\mathrm{CrO}_{3}\right)_{x} \mathrm{~K}_{\mathrm{y}}{ }^{-}$or $\left(\mathrm{CrO}_{3}\right)_{x} \mathrm{~K}_{\mathrm{y}} \mathrm{OH}^{-}$, where the number of potassium atoms is smaller than 2 at least below 1000 atomic mass unit (amu) sized clusters. Potassium probably originates from the metal wire as an impurity. downstream of the sampling line. The size dependent particle penetration, $P_{\text {line }}$ was measured between 1 and $5 \mathrm{~nm}$. The penetration of the ${ }^{14} \mathrm{C}$ charger, $P_{\text {charger, }}$ was measured in the same manner. Because of the ions generated inside the charger, the A11 was used to detect the particles downstream of the charger at supersaturation low enough for not to detect any ions generated by the radioactive source. In similar fashion, we measured the Half-mini DMA penetration, $P_{D M A}$, by guiding a known concentration of size selected chromium trioxide ions between 1 and $5 \mathrm{~nm}$ to the DMA, and scanning the corresponding voltage range with the DMA. The DMA resolution was measured by generating positively charged monomobile tetraheptylammonium $\left(\mathrm{THA}^{+}, \mathrm{C}_{28} \mathrm{H}_{60} \mathrm{~N}^{+}\right.$) ions (Ude and Fernández de la Mora 2005) with the Herrmann DMA, and scanning the corresponding voltage range with the Half-mini DMA. The DMA resolution is defined as $Z / \Delta Z$, where $\Delta Z$ is the full width at half maximum of measured with monomobile positively charged tetraheptylammonium ion at $1.47 \mathrm{~nm}$ (Flagan 1999). Particle losses in the t-split were evaluated by measuring the size dependent particle 
concentration exiting the Herrmann DMA at 5 L/Min directly and with the t-split, and by comparing the ratio of the concentrations. During this measurement the particle production was stable.

For the A11 detection efficiency, $P_{A 11}$, calibration we used two different test particle compositions to probe the composition dependent particle activation of DEG (Jiang et al. 2011a; Kangasluoma et al. 2014; Kangasluoma et al. 2016c). The particles were either chromium trioxide particles from the wire generator, or electrospray generated tetraheptylammonium bromide clusters (Ude and Fernández de la Mora 2005). In both cases the produced particles were charged with the ${ }^{241} \mathrm{Am}$ source before entering the Herrmann DMA, which size classified the negatively charged particles. After the size classification, the concentration detected by the A11 was compared against a TSI aerosol electrometer (3068B). The 3068B was operated at an inlet flow rate of $2.5 \mathrm{~L} / \mathrm{min}$ and with identical sampling lines as the A11 to avoid diffusion loss corrections.

\subsection{Atmospheric measurements}

The atmospheric measurements with the HFDMPS were performed in Hyytiälä, Finland, at SMEAR II measurement station (Hari and Kulmala 2005). The HFDMPS was sampling ambient air from 22.4 to 18.5.2017. The HFDMPS, sampling about $2 \mathrm{~m}$ above the ground level, was located in a container about 20 m away from the cottage of the Hyytiälä DMPS and NAIS, the former taking its sample through the roof of the cottage while the latter sampling through the wall of the cottage. Due to the small differences in the sampling locations, transient deviations can exist in the sampled particle populations, which even out in the longer data set.

The data inversion, following Stolzenburg and McMurry (2008), for the HFDMPS is performed as:

$$
\frac{\mathrm{d} N}{\mathrm{~d} \log _{10} D_{p}}=-\ln (10) \times \frac{C_{o b s}\left(D_{p}\right)}{P\left(D_{p}\right)} \frac{Q_{s}}{Q_{a}} \frac{\mathrm{d} \ln z_{p}}{\mathrm{~d} \ln D_{p}}
$$


where $\mathrm{d} N / \mathrm{d} / \log _{10} D_{p}$ is the inverted concentration, $C_{o b s}$ is the concentration observed by the CPC of the HFDMPS, $Q_{a}$ is the aerosol flow rate through the DMA, $Q_{s}$ is the DMA sheath flow rate and $Z_{p}$ is electrical mobility at $D_{p}$. As the largest size classified size is $10 \mathrm{~nm}$, we assume all particles to be singly charged. During the atmospheric experiments, we observed interference from background counts in our HFDMPS. This background count rate of the HFDMPS was measured to be on average 0.1 counts per second. As measurement time at each voltage was $10 \mathrm{~s}$ that would on average result in one count per measurement, we subtracted two counts from each measurement, and added one count to each measurement with counts more than three. Because of this, our detection limit is also three counts.

\section{Results and discussion}

\subsection{Characterization of the HFDMPS}

Earlier work indicate that the A11 detection efficiency depends on the chemical composition of the sampled particles (Kangasluoma et al. 2014). In Hyytiälä, boreal forest site, we can expect that the composition of freshly formed particles is strongly affected by low-volatile organic vapors (Ehn et al. 2014; Jokinen et al. 2017; Kulmala et al. 2013). Therefore, we conducted two separate calibrations for the A11: one with metal trioxides and another with hydrocarbon species, THABr. We selected $\mathrm{THABr}$ as the organic calibration compound, as currently no calibration methods exist which would produce oxidized pure organic atmospherically relevant aerosol particles at sufficiently high concentrations in sub- $10 \mathrm{~nm}$ size range in a controlled manner. The measured d50 values for the $\mathrm{CrO}_{3}$ and $\mathrm{THABr}$ particles were 1.4 and $2.0 \mathrm{~nm}$, respectively. Thus difference in the measured d50 values is $0.6 \mathrm{~nm}$. This has implications on the limitations of sub-3 nm DMPS measurements, when the particle composition is dominated by organic species, or any other particles exhibiting similar activation efficiencies with DEG. The problem related to composition specific particle activation is examined more in depth by Kangasluoma and Kontkanen (2017). This will be also elaborated in the section 3.3. 
Figure 2 presents the penetration efficiencies of the HFDMPS sampling lines (product of transport line, charger, t-split and the PSM), charging efficiency, the total penetration, $P$, the PtQ parameter relating directly the number of counted particles to the inverted size distribution, and the LOD of the HFDMPS as a function of particle diameter. The penetration efficiency is dominated by the theoretical charging efficiency, while the DMA and line penetration are relatively high.

The Half-mini DMA resolution with the operation settings of aerosol flow rate $5 \mathrm{~L} / \mathrm{min}$ and sheath flow rate $100 \mathrm{~L} / \mathrm{min}$ was approximately 7.8 at $1.47 \mathrm{~nm}$, which is in line with the measurements of Fernández de la Mora (2017). The theoretically estimated transfer functions are shown in Figure 3. The DMA penetration was measured up to $4.5 \mathrm{~nm}$ similarly as the other parameters, and then extrapolated up to $10 \mathrm{~nm}$. Function $1-\mathrm{e}^{-\mathrm{a}^{*} \mathrm{Dp}+\mathrm{b}}$ was fitted to the data. As reported by Fernández de la Mora (2017), this measured resolution at aerosol-to-sheath flow ratio of 0.05 deviates from the theoretical prediction of approximately 17 . This deviation is due to the slit type aerosol feeding, which causes non-ideal flow profiles to the aerosol entrance in the DMA. Further, this transfer function broadening can possibly cause particle losses in the size classification region, which are not taken into account in our extrapolation. Thus, it is possible that the DMA penetration is slightly overestimated, which leads to underestimated inverted size selected concentrations.

Possibly the largest uncertainty in $P$ accuracy are related to the particle charging probability, which we are unable to speculate here. The second largest uncertainty is related to the A11 detection efficiency in the sub-3 $\mathrm{nm}$ sizes. Previous experiments suggest that the $\mathrm{d} 50$ is approximately $2.5 \mathrm{~nm}$ for limonene ozonolysis products at similar DEG supersaturation as we operate here (Kangasluoma et al. 2014). This would suggest challenges, or at the very least, large uncertainties in our sub-3 nm measured particle concentrations. 


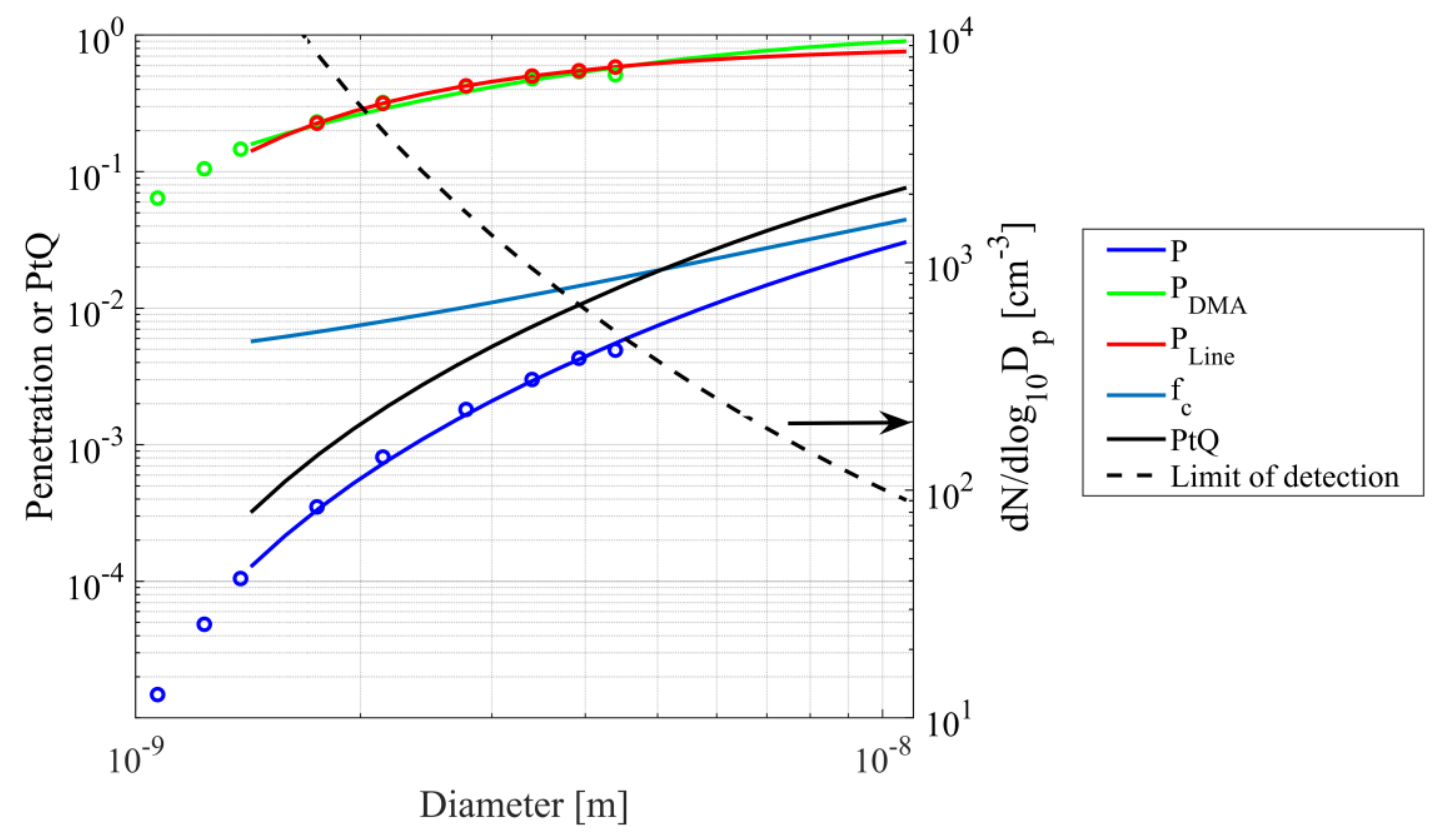

Figure 2. Penetrations, PtQ and limit of detection of the HFDMPS.

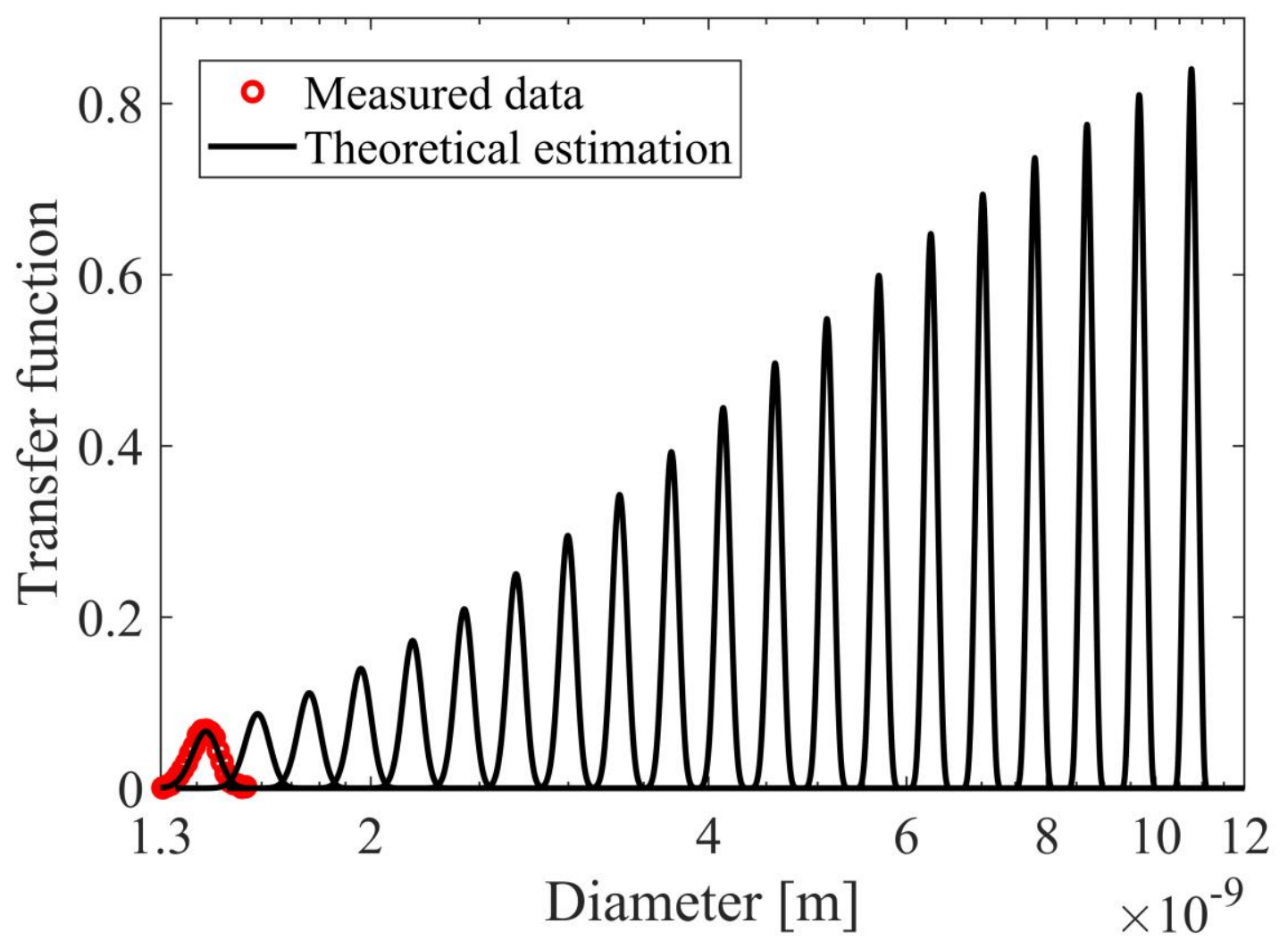
$100 \mathrm{~L} / \mathrm{min}$. 
From the atmospheric measurements we first discuss the measured 3-10 nm particle concentrations. The 3-10 nm particle concentration from the HFDMPS is directly compared to the Hyytiälä long-term DMPS, measuring about $20 \mathrm{~m}$ apart from the HFDMPS. On median during the measurement time period we find that the ratio of the detected concentrations between HFDMPS and DMPS is 1.78 (Figure 4). The particle concentrations measured by the two DMPS systems correlate linearly. The size dependent concentration ratio measured by the DMPS systems shows that at smaller sizes the DMPS concentration underestimation is larger, as expected. This is partly due to smaller sensitivity of the DMPS, and possibly partly due to incorrect loss corrections because of the lack of experimental sampling line characterization, which, if wrong, cause larger errors in the smallest particle sizes. As the HFDMPS counts more particles than the DMPS, and its PtQ value is also larger due to smaller sampling losses and less dilution in the CPC, its counting uncertainties are also smaller. The minimum uncertainty of a single measurement can be estimated from the Poisson uncertainty as the square root of the number of counted particles, $V N_{c}$, which is the $\sigma$ of the Poisson distribution (Kangasluoma and Kontkanen 2017). To compare the measurement uncertainties of the two DMPS systems, we selected time window of 10 am to $18 \mathrm{pm}$ from the 15 days of new particle formation during the campaign, and calculated the size dependent median number of counts and counting uncertainties (Table 1). Because of the larger $P$ and $Q$, and also PtQ value of the HFDMPS, the HFDMPS counts 3.5-9 times more raw counts than the DMPS depending on the particle size, and thereby the counting uncertainties are approximately two times smaller. 

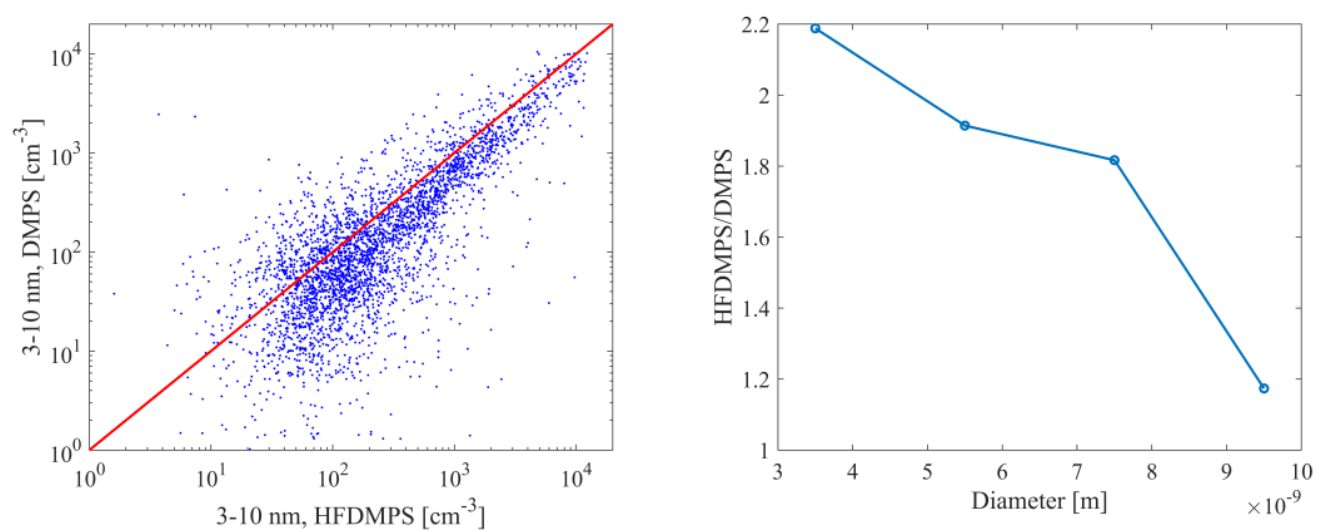

327 Figure 4. Left hand panel shows the comparison between the particle concentrations in the size range of 3-10 nm measured by the HFDMPS and the long-term DMPS. Solid red line is the 1:1 line. Right hand panel shows the size dependent ratio of the measured 3-10 $\mathrm{nm}$ particle concentrations in four different size classes.

Table 1. Size dependent median number of raw counts, $\mathrm{N}_{c},[\#]$ and counting uncertainties [\%] for the DMPS systems from 15 particle formation days.

\begin{tabular}{lllll} 
& $3-4.5 \mathrm{~nm}$ & $4.5-6.5 \mathrm{~nm}$ & $6.5-8.5 \mathrm{~nm}$ & $8.5-10 \mathrm{~nm}$ \\
\hline DMPS raw counts & 1 & 6 & 12 & 17 \\
HFDMPS raw counts & 9 & 21 & 40 & 81 \\
Ratio & 9.32 & 3.64 & 3.40 & 4.78 \\
& & & & \\
DMPS uncertainty & 72 & 40 & 29 & 25 \\
HFDMPS uncertainty & 33 & 22 & 16 & 11 \\
Ratio & 0.46 & 0.54 & 0.54 & 0.46
\end{tabular}

334

3.3 Implications to the limitations of DEG based DMPS technology to measure sub-3 $\mathrm{nm}$ particles

To examine the lowest detectable particle size of our HFDMPS in Hyytiälä conditions, we selected the strongest new particle formation event day (7.5.2017) from the observation period (Figure 5). The number size distribution immediately shows that only a very small concentration of particles is detected below $3 \mathrm{~nm}$ in size. This was the case during all other days when particle formation was observed. At channel $2.7 \mathrm{~nm}$ particles were detected only during a few scans, and practically no 
particles are detected below $2.4 \mathrm{~nm}$. This observation can have two explanations: either the A11 cannot detect particles smaller than $2.4 \mathrm{~nm}$ at the used supersaturation, which would be in qualitative agreement with Kangasluoma et al. (2014), presuming that the formed clusters were mainly composed of biogenic species. Another explanation would be that the atmospheric particle concentrations are below the HFDMPS detection limit.

We examine the performance of the HFDMPS in the sub-3 $\mathrm{nm}$ size range by comparing the HFDMPS LOD to particle concentrations measured by the NAIS. Figure 5 lower panel presents the ratio of the concentration measured by the NAIS and HFDMPS LOD. At $3 \mathrm{~nm}$ the NAIS detects particle concentrations that are approximately 5-10 times larger than the corresponding LOD of the HFDMPS, while also at $2.4 \mathrm{~nm}$ the concentration detected by the NAIS is often larger than the HFDMPS. The comparison between the particle concentrations detected by the NAIS at sizes $2.4,2.7$ and $3 \mathrm{~nm}$ 
smallest detectable particle size is somewhere around 2-3 $\mathrm{nm}$ in environments, where organic species dominate. This is in line with previous studies, which reported calibrations for DEG based CPCs with organic test aerosol (Jiang et al. 2011a; Kangasluoma et al. 2014). Few recent studies have reported atmospheric particle concentration measurements with DMPS systems even down to sub- $2 \mathrm{~nm}$ sizes (Cai and Jiang 2017; Jiang et al. 2011b; Kuang et al. 2012). The prerequisite for the success of such studies is that the particles can be detected with DEG. With the current knowledge, it is possible in environments, where the nanoparticle composition is dominated by e.g. sulfuric acid. This topic is still subject to large uncertainties because of lack of appropriate atmospherically relevant calibrations for the DEG based CPCs, and is similarly a challenge for supersaturation scan based experiments with the A11 (Kangasluoma and Kontkanen 2017).
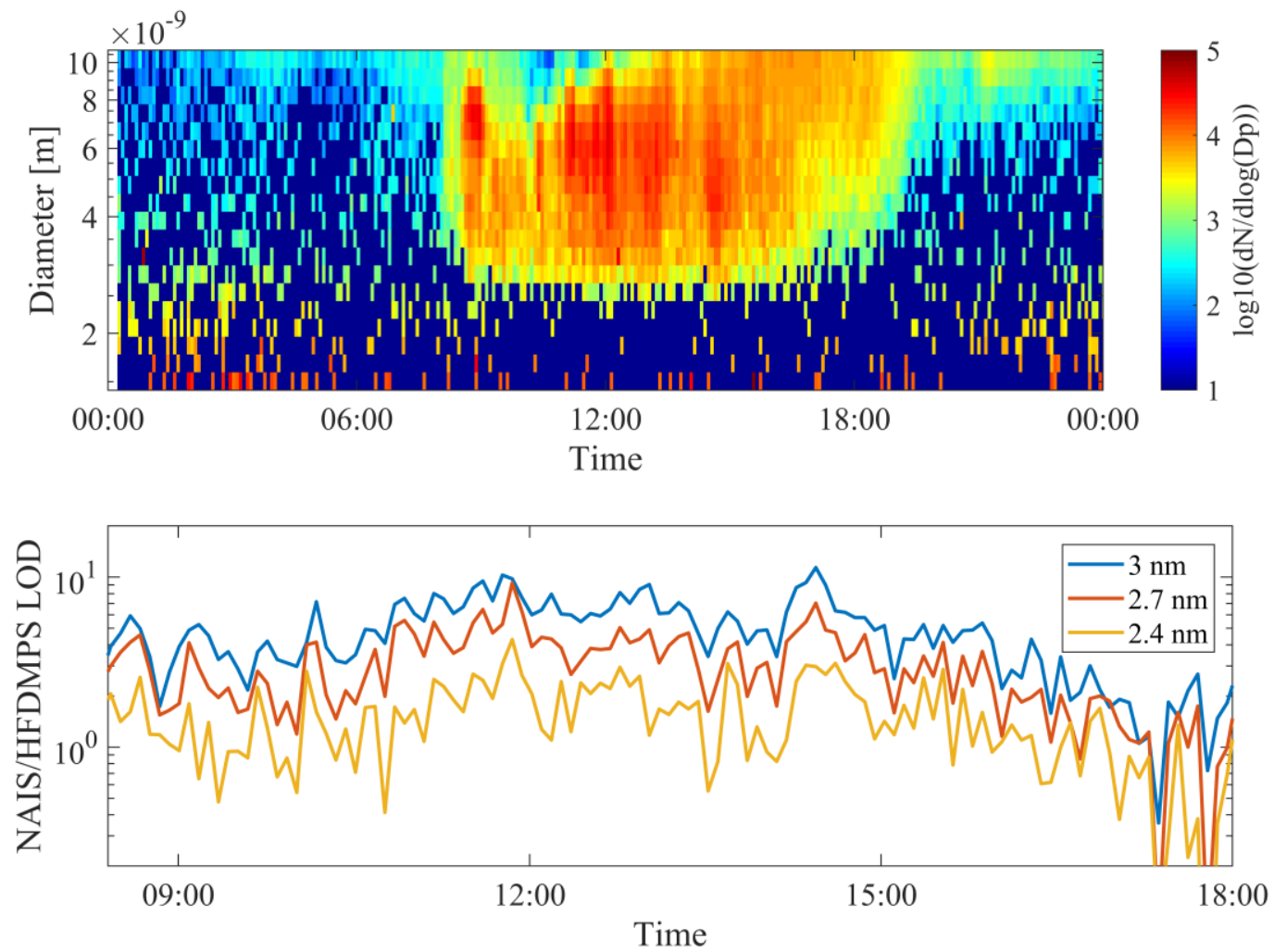

Figure 5. The upper panel shows a contour plot of a strong particle formation event on 7.5.2017. The limit of detection (LOD). Note the different time scales. 
Our observations have few general implications on sub-10 nm particle concentration measurements:

1) Optimization of sampling plays a crucial role in the accuracy of sub-10 $\mathrm{nm}$ particle 

the limit of charger ion sizes in the measurements of organic systems. Further, charging efficiencies should be explored in the laboratory with the state-of-the-art aerosol instrumentation, while further calibration efforts should be put forward to be able to characterize the DMPS performance with atmospherically relevant test aerosol. Finally, careful efforts to combine sub-3 $\mathrm{nm}$ size distribution measurements from DMPS and PSM should be put forward.

Acknowledgements

We are indebted to the Hyytiälä SMEARII station staff, J. Levula, S. Rantanen and M. Loponen, for taking care of the HFDMPS during the measurement campaign. We thank Prof. J. Fernandéz de la Mora for fruitful discussions. This work was partly funded by Maj and Tor Nessling foundation (grant 201700296), ACTRIS-2 (grant agreement number 654109), China Scholarship Council (CSC) and Academy of Finland (Center of Excellence Program projects 307331).

References

Aalto, P., Hameri, K., Becker, E., Weber, R., Salm, J., Makela, J. M., Hoell, C., O'Dowd, C. D., Karlsson, H., Hansson, H. C., Vakeva, M., Koponen, I. K., Buzorius, G., Kulmala, M. (2001). Physical Wiedensohler, A., Birmili, W., Hamed, A., O'Dowd, C., Jennings, S. G., Weller, R., Flentje, H., Fjaeraa, A. M., Fiebig, M., Myhre, C. L., Hallar, A. G., Swietlicki, E., Kristensson, A., Laj, P. (2013). Aerosol decadal trends - Part 2: In-situ aerosol particle number concentrations at GAW and ACTRIS stations. Atmos Chem Phys 13:895-916. 
Cai, R. and Jiang, J. (2017). A new balance formula to estimate new particle formation rate: reevaluating the effect of coagulation scavenging. Atmos Chem Phys 17:12659-12675.

Dada, L., Paasonen, P., Nieminen, T., Buenrostro Mazon, S., Kontkanen, J., Peräkylä, O., Lehtipalo, K., Hussein, T., Petäjä, T., Kerminen, V. M., Bäck, J., Kulmala, M. (2017). Long-term analysis of clear-sky new particle formation events and nonevents in Hyytiälä. Atmos Chem Phys 17:6227-6241.

Ehn, M., Thornton, J. A., Kleist, E., Sipilä, M., Junninen, H., Pullinen, I., Springer, M., Rubach, F., Tillmann, R., Lee, B., Lopez-Hilfiker, F., Andres, S., Acir, I. H., Rissanen, M., Jokinen, T., Schobesberger, S., Kangasluoma, J., Kontkanen, J., Nieminen, T., Kurten, T., Nielsen, L. B., Jorgensen, S., Kjaergaard, H. G., Canagaratna, M., Maso, M. D., Berndt, T., Petäjä, T., Wahner, A., Kerminen, V. M., Kulmala, M., Worsnop, D. R., Wildt, J., Mentel, T. F. (2014). A large source of low-volatility secondary organic aerosol. Nature 506:476-479.

Fernández de la Mora, J. (2011). Ionization of vapor molecules by an electrospray cloud. Int J Mass Spectrom 300:182-193.

Fernández de la Mora, J. (2017). Expanded flow rate range of high-resolution nanoDMAs via improved sample flow injection at the aerosol inlet slit. J Aerosol Sci 113:265-275.

Fernández de la Mora, J. and Kozlowski, J. (2013). Hand-held differential mobility analyzers of high resolution for 1-30 nm particles: Design and fabrication considerations. J Aerosol Sci 57:45-53.

Flagan, R. C. (1999). On differential mobility analyzer resolution. Aerosol Science and Technology 30:556-570.

Fuchs, N. A. (1963). On the stationary charge distribution on aerosol particles in a bipolar ionic atmosphere. Geofis. Pura Appl. 56:185-193.

Hari, P. and Kulmala, M. (2005). Station for measuring ecosystem-atmosphere relations (SMEAR II). Boreal Environ Res 10:315-322.

lida, K., Stolzenburg, M. R., McMurry, P. H. (2009). Effect of Working Fluid on Sub-2 nm Particle Detection with a Laminar Flow Ultrafine Condensation Particle Counter. Aerosol Sci Tech 43:81-96.

Jiang, J. K., Chen, M. D., Kuang, C. A., Attoui, M., McMurry, P. H. (2011a). Electrical Mobility Spectrometer Using a Diethylene Glycol Condensation Particle Counter for Measurement of Aerosol Size Distributions Down to $1 \mathrm{~nm}$. Aerosol Sci Tech 45:510-521.

Jiang, J. K., Zhao, J., Chen, M. D., Eisele, F. L., Scheckman, J., Williams, B. J., Kuang, C. A., McMurry, P. H. (2011b). First Measurements of Neutral Atmospheric Cluster and 1-2 nm Particle Number Size Distributions During Nucleation Events. Aerosol Sci Tech 45:2-5. 
Jokinen, T., Kontkanen, J., Lehtipalo, K., Manninen, H. E., Aalto, J., Porcar-Castell, A., Garmash, O., Nieminen, T., Ehn, M., Kangasluoma, J., Junninen, H., Levula, J., Duplissy, J., Ahonen, L. R., Rantala, P., Heikkinen, L., Yan, C., Sipila, M., Worsnop, D. R., Back, J., Petaja, T., Kerminen, V. M., Kulmala, M. (2017). Solar eclipse demonstrating the importance of photochemistry in new particle formation. Sci Rep-Uk 7.

Jokinen, V. and Mäkelä, J. M. (1997). Closed-loop arrangement with critical orifice for DMA sheath excess flow system. J Aerosol Sci 28:643-648.

Kangasluoma, J., Ahonen, L., Attoui, M., Vuollekoski, H., Kulmala, M., Petäjä, T. (2015a). Sub-3 nm Particle Detection with Commercial TSI 3772 and Airmodus A20 Fine Condensation Particle Counters. Aerosol Sci Tech 49:674-681.

Kangasluoma, J., Attoui, M., Junninen, H., Lehtipalo, K., Samodurov, A., Korhonen, F., Sarnela, N., Schmidt-Ott, A., Worsnop, D., Kulmala, M., Petaja, T. (2015b). Sizing of neutral sub $3 \mathrm{~nm}$ tungsten oxide clusters using Airmodus Particle Size Magnifier. J Aerosol Sci 87:53-62.

Kangasluoma, J., Attoui, M., Korhonen, F., Ahonen, L., Siivola, E., Petäjä, T. (2016a). Characterization of a Herrmann type high resolution differential mobility analyzer. Aerosol Sci Tech 50:222-229.

Kangasluoma, J., Franchin, A., Duplissy, J., Ahonen, L., Korhonen, F., Attoui, M., Mikkilä, J., Lehtipalo, K., Vanhanen, J., Kulmala, M., Petäjä, T. (2016b). Operation of the Airmodus A11 nano Condensation Nucleus Counter at various inlet pressures, various operation temperatures and design of a new inlet system. Atmos Meas Tech 9:2977-2988.

Kangasluoma, J. and Kontkanen, J. (2017). On the sources of uncertainty in the sub- $3 \mathrm{~nm}$ particle concentration measurement. J Aerosol Sci 112:34-51.

Kangasluoma, J., Kuang, C., Wimmer, D., Rissanen, M. P., Lehtipalo, K., Ehn, M., Worsnop, D. R., Wang, J., Kulmala, M., Petaja, T. (2014). Sub-3 nm particle size and composition dependent response of a nano-CPC battery. Atmos Meas Tech 7:689-700.

Kangasluoma, J., Samodurov, A., Attoui, M., Franchin, A., Junninen, H., Korhonen, F., Kurtén, T., Vehkamäki, H., Sipilä, M., Lehtipalo, K., Worsnop, D., Petäjä, T., Kulmala, M. (2016c). Heterogeneous nucleation onto ions and neutralized ions - insights into sign-preference. Journal of Physical Chemistry C 120:7444-7450.

Kuang, C., Chen, M., Zhao, J., Smith, J., McMurry, P. H., Wang, J. (2012). Size and time-resolved growth rate measurements of 1 to $5 \mathrm{~nm}$ freshly formed atmospheric nuclei. Atmos Chem Phys 12:3573-3589.

Kulmala, M., Kontkanen, J., Junninen, H., Lehtipalo, K., Manninen, H. E., Nieminen, T., Petaja, T., Sipila, M., Schobesberger, S., Rantala, P., Franchin, A., Jokinen, T., Jarvinen, E., Aijala, M., Kangasluoma, J., Hakala, J., Aalto, P. P., Paasonen, P., Mikkila, J., Vanhanen, J., Aalto, J., Hakola, H., Makkonen, U., Ruuskanen, T., Mauldin, R. L., Duplissy, J., Vehkamaki, H., Back, J., Kortelainen, A., Riipinen, I., Kurten, T., Johnston, M. V., Smith, J. N., Ehn, M., Mentel, T. F., Lehtinen, K. E. J., 
Laaksonen, A., Kerminen, V. M., Worsnop, D. R. (2013). Direct Observations of Atmospheric Aerosol Nucleation. Science 339:943-946.

Kulmala, M., Petaja, T., Nieminen, T., Sipila, M., Manninen, H. E., Lehtipalo, K., Dal Maso, M., Aalto, P. P., Junninen, H., Paasonen, P., Riipinen, I., Lehtinen, K. E. J., Laaksonen, A., Kerminen, V. M. (2012). Measurement of the nucleation of atmospheric aerosol particles. Nat Protoc 7:1651-1667.

Lehtipalo, K., Leppa, J., Kontkanen, J., Kangasluoma, J., Franchin, A., Wimnner, D., Schobesberger, S., Junninen, H., Petaja, T., Sipila, M., Mikkila, J., Vanhanen, J., Worsnop, D. R., Kulmala, M. (2014). Methods for determining particle size distribution and growth rates between 1 and $3 \mathrm{~nm}$ using the Particle Size Magnifier. Boreal Environ Res 19:215-236.

Manninen, H. E., Mirme, S., Mirme, A., Petäjä, T., Kulmala, M. (2016). How to reliably detect molecular clusters and nucleation mode particles with Neutral cluster and Air lon Spectrometer (NAIS). Atmos Meas Tech 9:3577-3605.

Mirme, S. and Mirme, A. (2013). The mathematical principles and design of the NAIS - a spectrometer for the measurement of cluster ion and nanometer aerosol size distributions. Atmos Meas Tech 6:1061-1071.

Peineke, C., Attoui, M. B., Schmidt-Ott, A. (2006). Using a glowing wire generator for production of charged, uniformly sized nanoparticles at high concentrations. J Aerosol Sci 37:1651-1661.

Pfeifer, S., Birmili, W., Schladitz, A., Muller, T., Nowak, A., Wiedensohler, A. (2014). A fast and easyto-implement inversion algorithm for mobility particle size spectrometers considering particle number size distribution information outside of the detection range. Atmos Meas Tech 7:95-105.

Rose, C., Sellegri, K., Asmi, E., Hervo, M., Freney, E., Colomb, A., Junninen, H., Duplissy, J., Sipila, M., Kontkanen, J., Lehtipalo, K., Kulmala, M. (2015). Major contribution of neutral clusters to new particle formation at the interface between the boundary layer and the free troposphere. Atmos Chem Phys 15:3413-3428.

Stolzenburg, D., Steiner, G., Winkler, P. M. (2017). A DMA-train for precision measurement of sub-10 $\mathrm{nm}$ aerosol dynamics. Atmos Meas Tech 10:1639-1651.

Stolzenburg, M. R. and McMurry, P. H. (2008). Equations governing single and tandem DMA configurations and a new lognormal approximation to the transfer function. Aerosol Sci Tech 42:421432.

Stolzenburg, M. R., Scheckman, J. H. T., Attoui, M., Han, H. S., McMurry, P. H. (2018). Characterization of the TSI model 3086 differential mobility analyzer for classifying aerosols down to $1 \mathrm{~nm}$. Aerosol Sci Tech. 
Tuch, T., Brand, P., Wichmann, H. E., Heyder, J. (1997). Variation of particle number and mass concentration in various size ranges of ambient aerosols in Eastern Germany. Atmos Environ 31:4193-4197.

Ude, S. and Fernández de la Mora, J. (2005). Molecular monodisperse mobility and mass standards from electrosprays of tetra-alkyl ammonium halides. Journal of Aerosol Science 36:1224-1237.

Vanhanen, J., Mikkila, J., Lehtipalo, K., Sipila, M., Manninen, H. E., Siivola, E., Petaja, T., Kulmala, M. (2011). Particle Size Magnifier for Nano-CN Detection. Aerosol Sci Tech 45:533-542.

Wehner, B. and Wiedensohler, A. (2003). Long term measurements of submicrometer urban aerosols: statistical analysis for correlations with meteorological conditions and trace gases. Atmos Chem Phys 3:867-879.

Wiedensohler, A. (1988). An approximation of the bipolar charge distribution for particles in the submicron size range. J Aerosol Sci 19:387-389.

Wiedensohler, A., Birmili, W., Nowak, A., Sonntag, A., Weinhold, K., Merkel, M., Wehner, B., Tuch, T., Pfeifer, S., Fiebig, M., Fjaraa, A. M., Asmi, E., Sellegri, K., Depuy, R., Venzac, H., Villani, P., Laj, P., Aalto, P., Ogren, J. A., Swietlicki, E., Williams, P., Roldin, P., Quincey, P., Huglin, C., FierzSchmidhauser, R., Gysel, M., Weingartner, E., Riccobono, F., Santos, S., Gruning, C., Faloon, K., Beddows, D., Harrison, R. M., Monahan, C., Jennings, S. G., O'Dowd, C. D., Marinoni, A., Horn, H. G., Keck, L., Jiang, J., Scheckman, J., McMurry, P. H., Deng, Z., Zhao, C. S., Moerman, M., Henzing, B., de Leeuw, G., Loschau, G., Bastian, S. (2012). Mobility particle size spectrometers: harmonization of technical standards and data structure to facilitate high quality long-term observations of atmospheric particle number size distributions. Atmos Meas Tech 5:657-685.

Winklmayr, W., Reischl, G. P., Lindner, A. O., Berner, A. (1991). A New Electromobility Spectrometer for the Measurement of Aerosol Size Distributions in the Size Range from 1 to $1000 \mathrm{Nm}$. J Aerosol Sci 22:289-296. 